\title{
ADHERENCE TO PULSE THERAPY WITH CYCLOPHOSPHAMIDE IN PATIENTS WITH RHEUMATOLOGIC DISORDERS
}

Aline Sales Vasconcelos ${ }^{1, \star}$, Lia Poti Gomes Cordeiro², João Alexandre Guerra Moita², Victoria Benigno Moreira Da Rocha ${ }^{3}$, Isa Cavalcanti Martildes ${ }^{3}$, Samily Cordeiro De Oliveira ${ }^{4}$, Guillherme Nobre Cavalcanti Lucas ${ }^{3}$, André Xenofonte Cartaxo Sampaio', Carlos Ewerton Maia Rodrigues ${ }^{3}$, Kirla Wagner Poti Gomes ${ }^{3}$

1.Hospital Geral de Fortaleza, Fortaleza (CE), Brazil. 2.Centro Universitário Christus, Fortaleza (CE), Brazil. 3.Universidade de Fortaleza, Fortaleza (CE), Brazil. 4.Universidade Federal do Ceará, Fortaleza (CE), Brazil.

${ }^{\star}$ Corresponding author: lininha_sv@yahoo.com.br

\section{BACKGROUND}

Pulse therapy with cyclophosphamide is a treatment used in several rheumatological diseases when there is a rapid and intense evolution of an acute inflammatory condition, with life-threatening systemic repercussions. The present study aimed to analyze adherence to treatment with cyclophosphamide in patients at the Rheumatology Service of Hospital Geral de Fortaleza.

\section{MATERIALS AND METHODS}

A retrospective study was carried out and data collection was performed using information from the medical records of patients who underwent pulse therapy between January 2018 and September 2019. An intervention was made through telephone calls to confirm the day of the infusion and, afterwards, the adherence rate of before and after the intervention was compared, with $p<0.05$ being considered significant.

\section{RESULTS}

108 patients were included; the majority were female (83.3\%) and the average age was 37.5 years. Most patients were not from Fortaleza (56.3\%). The most frequent pathology was systemic lupus erythematosus $(75.9 \%)$, with lupus nephritis being the main indication for pulse therapy (65.7\%). Other diseases found were systemic sclerosis (10.1\%), primary vasculitis (4.6\%), mixed connective tissue disease (3.7\%), Sjögren's syndrome (2.7\%), pulmonary fibrosis with unknown etiology (2.7\%), discoid lupus (1.8\%) and antisynthetase syndrome (1.8\%). During the study period, 637 infusions were programmed and 477 (75.0\%) were performed. Before phone calls, $73 \%$ of the scheduled doses were made, increasing to $78 \%$ after calls ( $p=0.1103$ ). The main reason for nonadherence was infection (47.4\%), followed by hospitalization (12.3\%), failure to realize laboratory tests (10.5\%) and unknown reasons $(29.9 \%)$.

\section{CONCLUSION}

Adherence to treatment with cyclophosphamide was influenced by multiple factors, especially the side effects of the medication, such as infections, and those inherent to the chronic condition of the underlying disease. Although it was not evaluated, the distance between the patient's city of origin and the hospital may have contributed to absences and rescheduling, since most patients lived in another city. Despite the intervention made through telephone calls, the adherence rate did not increase significantly. Therefore, it is necessary to carry out further studies to know all possible reasons that contribute to poor adherence to treatment, so more appropriate interventions can be made. 